\title{
EFFECT OF FROSTING, MOISTURE STRESS AND POTASSIUM CYANIDE ON THE METABOLISM OF CYANOGENIC AND ACYANOGENIC PHENOTYPES OF LOTUS CORNICULATUS L. AND TRIFOLIUM REPENS L.
}

\author{
W. FOULDS \\ Science Department, Claremont Teachers College, West Australia \\ and \\ L. YOUNG \\ Science Department, Dudley College of Education, Worcestershire
}

Received 18.vi.76

\section{Summary}

KCN artificially added to leaves of cyanogenic and acyanogenic forms of $L$. corniculatus and $T$. repens at concentrations found in white clover plants reduced photosynthesis to zero. At the same concentration, respiration was only inhibited in the cyanogenic phenotype of T. repens. Higher concentrations of KCN inhibited respiration in both species but to a greater degree in the cyanogenic form of $T$. repens.

Frosting and severely droughting entire plants generally reduced photosynthesis but had no effect on respiration in both species, irrespective of the presence of cyanide.

\section{INTRODUGTION}

Damage to tissues of the cyanogenic phenotype of $L$. corniculatus and $T$. repens releases detectable amounts of HCN (Melville et al., 1940). Two suggested climatic factors responsible for the release of cyanide are frosting (Daday, 1965) and soil moisture stress (Foulds and Grime, 1972). Daday proposed that the selection exerted by frosting against cyanogenic plants of $T$. repens is due to the activation of linamarase, release of HCN from the glucoside and the irreversible inhibition of respiration resulting in tissue death.

Cyanide is a very unspecific enzyme inhibitor. It inhibits a large number of enzymes which do not involve a metal catalysis as well as a number that do contain metals, e.g. it combines with iron in cytochrome oxidase, thus inhibiting respiration (Marsh and Goddard, 1939; Dixon and Webb, 1966; Lundegårdh, 1966).

The strongest concentration of $\mathrm{HCN}$ recorded in single cyanogenic plants of T. repens was 500 p.p.m. (green weight) by Melville et al. (1940), but Corkill (1940) found that among clover strains the highest value obtained was 350 p.p.m. on a green weight basis, and this doubtless represents the maximum obtainable under pasture conditions. Leaves of the cyanogenic phenotype of $L$. corniculatus during flowering can contain 98 p.p.m. per green weight (Zhukovski, 1956).

The following experiments were devised to test the hypothesis that the HCN released from the leaves of cyanogenic plants of $L$. corniculatus and $T$. repens by the two agents, frosting and moisture stress, inhibits respiration 
and possibly photosynthesis. The effect of 350 and 1000 p.p.m. potassium cyanide on both cyanogenic and acyanogenic phenotypes of the two species was also investigated.

\section{Materials and methods}

The rate of photosynthesis and respiration of treated and control leaves was measured by using a circular Warburg apparatus (Model VL 166). Lighting was provided by bulbs which gave a light intensity of 1200 lux at flask level and the temperature was maintained at $30^{\circ} \mathrm{C}$.

To test the effect of frosting on detached leaves, samples of shoots taken from 10 plants of each phenotype of both legume species were put into a beaker of water which was placed in a refrigerator at $1^{\circ} \mathrm{C}\left( \pm 0.5^{\circ} \mathrm{C}\right)$ for 18 hours. The most recently opened trefoils werc then detached from the shoots and placed on a gauze floating on deionised water at $22^{\circ} \mathrm{C}$ for 1 hour. Untreated leaves from shoots which had been kept at $22^{\circ} \mathrm{C}$ for a similar period were also placed on gauze. After this initial period of equilibrium on the gauze, five leaves of each phenotype were placed, abaxial surface uppermost, in a Warburg flask, using $0.5 \mathrm{~cm}^{3}$ of diethanolamine in the centre well. (This buffer gives a constant carbon dioxide concentration of approximately 1 per cent.) The effect of frosting on the metabolic processes of leaves while still attached to the plant was measured by placing 10 whole potted plants (similar to those in the previous experiment) in a refrigerator at $1^{\circ} \mathrm{C}$ for 18 hours. A similar number of plants were kept in the dark at $22^{\circ} \mathrm{C}$ for the same period of time. Samples of the most recently opened leaves were collected from the treated and untreated plants and placed in the same equilibrium equipment as before.

The effect of the droughting on the two metabolic processes was tested by allowing cyanogenic and acyanogenic plants of the two species to dry until the leaves had wilted for 4 days. Samples of recently opened leaves of droughted and control individuals (kept moist for the same period of time) were then cut from the plants and measurements made (after equilibration).

The fourth experiment consisted of taking 10 sets of five untreated leaves as before and placing them in a Warburg flask which contained $0.5 \mathrm{~cm}^{3}$ of $\mathrm{KCN}$ (350 or 1000 p.p.m.). Ten sets of control leaves were placed in flasks that contained $0.5 \mathrm{~cm}^{3}$ of deionised water.

All means were compared by the use of a " $l$ " test and the null hypotheses are of the usual two-tailed kind.

\section{Results}

The rate of photosynthesis of detached leaves of cyanogenic and acyanogenic phenotypes of $L$. corniculatus, when frosted, was reduced by 75 per cent $(P<0.001)$ when compared with the untreated leaves (table 1$)$. However, the same metabolic process in the acyanogenic phenotypes of $\mathcal{T}$. repens was unaffected by the treatment but the cyanogenic form was significantly reduced $(0.01>\mathrm{P}>0.001)$. There was a slight stimulation in the rate of respiration in cyanogenic and acyanogenic forms of both species of legume but this was only significant in the case of the acyanogenic phenotype of $T$. repens. Frosting of entire plants for a period of 18 hours at $1^{\circ} \mathrm{C}$ 
had no significant effect on respiration of leaves of either species, whether cyanogenic or acyanogenic (table 2). Photosynthesis was only inhibited significantly in the cyanogenic form of $L$. corniculatus $(0 \cdot 05>\mathrm{P}>0.01)$ and the acyanogenic phenotype of $T$. repens $(\mathrm{P}<0 \cdot 001)$.

The droughting of plants sufficient to cause the leaves to be wilted for 4 days and reduce the relative water content to approximately 40 per cent inhibited the rate of photosynthesis of cyanogenic and acyanogenic leaves

\section{TABLE 1}

The effect of frosting $\left(1^{\circ} \mathrm{C}\right.$ for 18 hours) on the rate of photosynthesis and respiration of detached cyanogenic and acyanogenic leaves of $\mathrm{L}$. corniculatus and $\mathrm{T}$. repens. (Gas exchanges are as microlitres oxygen exchanged per $g$ dry weight per hour)

\begin{tabular}{|c|c|c|c|c|c|}
\hline \multirow{2}{*}{$\begin{array}{c}\text { Species } \\
\text { phenotype }\end{array}$} & \multirow{2}{*}{$\begin{array}{c}\text { No. of } \\
\text { measure- } \\
\text { ments }\end{array}$} & \multicolumn{2}{|c|}{ Photosynthesis } & \multicolumn{2}{|c|}{ Respiration } \\
\hline & & Control & Frosted & Control & Frosted \\
\hline \multicolumn{6}{|l|}{ L. corniculatus } \\
\hline Cyanogenic & 6 & $41 \cdot 34(2 \cdot 49) \dagger$ & $8 \cdot 84(0 \cdot 8)$ & $3.77(0.51)$ & $4.24(0.49)$ \\
\hline Acyanogenic* & 16 & $44.87(3.97)$ & $12 \cdot 16(1 \cdot 67)$ & $3.77(0.50)$ & $2 \cdot 70(0 \cdot 48)$ \\
\hline \multicolumn{6}{|l|}{ T. repens } \\
\hline Cyanogenic & 12 & $42 \cdot 12(2 \cdot 68)$ & $31 \cdot 24(2 \cdot 46)$ & $3 \cdot 21(0 \cdot 41)$ & $3.96(0.30)$ \\
\hline Acyanogenic* & 18 & $34 \cdot 15(1.91)$ & $34 \cdot 15(2 \cdot 07)$ & $3 \cdot 07(0 \cdot 14)$ & $3.84(0.16)$ \\
\hline
\end{tabular}

TABLE 2

The effect of frosting $\left(1^{\circ} \mathrm{C}\right.$ for 18 hours) on the rate of photosynthesis and respiration of attached leaves of cyanogenic and acyanogenic phenotypes of $\mathrm{L}$. corniculatus and $\mathrm{T}$. repens. (Gas exchanges are as microlitres of oxygen exchanged per $g$ dry weight per hour)

\begin{tabular}{|c|c|c|c|c|c|}
\hline \multirow{2}{*}{$\begin{array}{c}\text { Species } \\
\text { phenotype }\end{array}$} & \multirow{2}{*}{$\begin{array}{l}\text { No. of } \\
\text { measure- } \\
\text { ments }\end{array}$} & \multicolumn{2}{|c|}{ Photosynthesis } & \multicolumn{2}{|c|}{ Respiration } \\
\hline & & Control & Frosted & Control & Frosted \\
\hline corniculatus & & & & & \\
\hline Cyanogenic & 12 & $37.93(3.30) \dagger$ & $26 \cdot 78(2 \cdot 35)$ & $4.05(0.53)$ & $3.70(0.29)$ \\
\hline $\begin{array}{l}\text { Acyanogenic* } \\
\text { repens }\end{array}$ & 20 & $46 \cdot 38(5 \cdot 02)$ & $40.87(3.55)$ & $2 \cdot 88(0.45)$ & $3.48(0.26)$ \\
\hline Cyanogenic & 18 & $29.23(2.51)$ & $22.86(3.20)$ & $4 \cdot 22(0 \cdot 31)$ & $3.42(0.22)$ \\
\hline Acyanogenic & 36 & $35.89(1.46)$ & $30.95(1.75)$ & $3.39(0 \cdot 16)$ & $3.75(0.27)$ \\
\hline
\end{tabular}

* Includes measurements on all three acyanogenic phenotypes.

$\uparrow$ The entries in brackets represent the standard error of the mean.

of both species, particularly those of $L$. corniculatus. (Table 3 ) Except for the acyanogenic phenotypes of $L$. corniculatus $(0.01>\mathrm{P}>0.001)$ there was no significant reduction in the rate of respiration of the two species whether they possessed cyanide or not.

Potassium cyanide solution (350 and 1000 p.p.m.) added to the leaves of cyanogenic and acyanogenic phenotypes of $L$. corniculatus and $T$. repens completely inhibited photosynthesis in both species (table 4). With the exception of the cyanogenic phenotype of $T$. repens $(0.05>\mathrm{P}>0.01)$ there was no significant difference in the rate of respiration between the phenotypes of either of the two species after the addition of 350 p.p.m. KGN. However, a concentration of 1000 p.p.m. reduced by over 80 per cent the 
respiration of both cyanogenic and acyanogenic phenotypes of $\mathcal{T}$. repens $(\mathbf{P}<0.001)$, to a lesser extent the respiration of the acyanogenic forms of L. corniculatus ( 72 per cent, $\mathrm{P}<0.001)$, and there was only a 40 per cent reduction in leaves of the cyanogenic form $(\mathrm{P}<0 \cdot 001)$. There was a significant difference between the treatment means of $L$. corniculatus $(\mathrm{P}<0.001)$ but not those of $\mathcal{T}$. repens.

TABLE 3

The effect of drought (wilting for 4 days) on the rate of photosynthesis and respiration of the leaves of cyanogenic and acyanogenic phenotypes of $\mathrm{L}$. corniculatus and $\mathrm{T}$. repens. (Cas exchanges are as mircrolitres oxygen exchanged per $g$ dry weight per hour)

No. of $\begin{gathered}\text { Neasure- } \\ \text { ments }\end{gathered}$
Undroughted $\overbrace{\text { Droughted }}^{\text {Photosynthesis }} \overbrace{\text { Undroughted Droughted }}^{\text {Respiration }}$

\begin{tabular}{|c|c|c|c|c|c|}
\hline \multicolumn{6}{|l|}{ L. corniculatus } \\
\hline Cyanogenic & 8 & $24 \cdot 22(1 \cdot 36) \dagger$ & $10 \cdot 15(0 \cdot 70)$ & $2.57(0 \cdot 16)$ & $2 \cdot 68(0 \cdot 08)$ \\
\hline Acyanogenic* & 22 & $26.45(1.90)$ & $10.86(0.99)$ & $4.33(0.37)$ & $3.04(0.18)$ \\
\hline \multicolumn{6}{|l|}{$T$. repens } \\
\hline Cyanogenic & 20 & $29.40(3.96)$ & $17 \cdot 96(3 \cdot 72)$ & $2 \cdot 68(0.11)$ & $2.65(0.11)$ \\
\hline Acyanogenic* & 26 & $35 \cdot 27(2 \cdot 67)$ & $17.92(1.92)$ & $2.57(0.09)$ & $2.78(0.15)$ \\
\hline
\end{tabular}

* Includes mcasurcments on all three acyanogenic phenotypes.

$\dagger$ The entries in brackets represent the standard error of the mean.

TABIE: 4

The effect of $K C \mathrm{~N}$ (350 and 1000 p.p.m.) on the rate of photosynthesis and respiration of leaves of cyanogenic and acyanogenic phenotypes of $\mathrm{L}$. corniculatus and $\mathrm{T}$. repens. (Gas exchanges are as microlitres oxygen exchanged per $g$ dry weight per hour)

\begin{tabular}{|c|c|c|c|c|c|}
\hline \multirow{2}{*}{$\begin{array}{c}\text { Species } \\
\text { phenotype }\end{array}$} & \multirow{2}{*}{$\begin{array}{l}\text { No. of } \\
\text { measure- } \\
\text { ments }\end{array}$} & \multicolumn{2}{|c|}{ Photosynthesis } & \multicolumn{2}{|c|}{ Respiration } \\
\hline & & Control & 350 p.p.m. KCN & Ciontrol & 350 p.p.m. KG \\
\hline \multicolumn{6}{|l|}{ L. corniculatus } \\
\hline Cyanogenic & 10 & $38.66(3.47) \dagger$ & $0 \cdot 00$ & $2 \cdot 68(0.24)$ & $2 \cdot 42(0.24)$ \\
\hline Acyanogenic* & 10 & $26 \cdot 16(1 \cdot 77)$ & $0 \cdot 00$ & $2 \cdot 75(0 \cdot 24)$ & $2 \cdot 48(0 \cdot 20)$ \\
\hline \multicolumn{6}{|l|}{$T$. repens } \\
\hline Cyanogenic & 10 & $49 \cdot 63(1 \cdot 97)$ & 0.00 & $3.12(0.41)$ & $2.58(0 \cdot 22)$ \\
\hline \multirow[t]{2}{*}{ Acyanogenic* } & 10 & $46 \cdot 87(1.66)$ & $0 \cdot 00$ & $2.98(0.37)$ & $2.49(0.31)$ \\
\hline & & \multicolumn{2}{|c|}{ Control 1000 p.p.m. KCN } & \multicolumn{2}{|c|}{ Control 1000 p.p.m. KCB } \\
\hline \multicolumn{6}{|l|}{ L. corniculatus } \\
\hline Cyanogenic & 5 & $40 \cdot 16(1 \cdot 09)$ & $0 \cdot 00$ & $3.53(0.30)$ & $2 \cdot 12(0 \cdot 16)$ \\
\hline Acyanogenic* & 5 & $42 \cdot 24(1 \cdot 74)$ & $0 \cdot 00$ & $4 \cdot 38(0 \cdot 26)$ & $1 \cdot 22(0 \cdot 10)$ \\
\hline \multicolumn{6}{|l|}{ T. repens } \\
\hline Cyanogenic & 5 & $40 \cdot 64(0 \cdot 89)$ & 0.00 & $3 \cdot 30(0 \cdot 31)$ & $0.45(0.08)$ \\
\hline Acyanogenic* & 5 & $37.56(1.56)$ & $0 \cdot 00$ & $2 \cdot 02(0.05)$ & $0.40(0.06)$ \\
\hline
\end{tabular}

* Inclucles measurements on more than one type of acyanogenic phenotypc.

$\dagger$ The critrics in brackets represent the standard error of the mean.

\section{Discusssion}

The present study indicates that should cyanide be released in the leaves of cyanogenic forms of $L$. corniculatus and $\mathcal{T}$. repens at concentrations recorded by Corkill, 1952 (350 p.p.m.), the effect is greater on the enzymes concerned with photosynthesis than respiration. This conclusion is possible 
despite the inability of the Warburg apparatus to measure photorespiration. 'The results suggest that photosynthesis, and not photorespiration, is inhibited by the cyanide; otherwise, if the reverse were the case, the CN treated leaves would possess higher rates of photosynthesis than the controls. When KCN was added at a concentration of 350 p.p.m. then photosynthesis was completely inhibited in all leaves but dark respiration was only inhibited in the cyanogenic phenotype of $\mathcal{T}$. repens.

The addition of 1000 p.p.m. CN (above that suggested by Corkill, 1952 (350 p.p.m.) and Melville et al., 1940 (500 p.p.m.)), again completely inhibited photosynthesis in all phenotypes of the two species. Respiration was also inhibited in all forms of the two legumes but to a greater degree in tissues of $T$. repens; the cyanogenic phenotype of $T$. repens was the greatest affected and the cyanogenic phenotype of $L$. corniculatus was the least affected at this higher concentration of KCN. Thus it appears that the enzymes concerned with photosynthesis are more sensitive to the two concentrations of $\mathrm{KCN}$ used than those of respiration, and this latter process is affected to a greater extent in tissues of $T$. repens than those of $L$. corniculatus.

One short period of frosting had no effect on the rate of respiration of either of the phenotypes in $L$. corniculatus or $T$. repens. However, photosynthesis was inhibited to a slight degree but with no greater effect on the cyanogenic as compared with the acyanogenic phenotypes. This could mean that the treatment was either not sufficiently severe or not sufficiently prolonged to release the cyanide in cyanogenic leaves. In any case, Jones (1972) proposed that winter temperature may be much less important in determining the distribution of cyanogenic forms of $L$. corniculatus in European populations.

Daday $(1954 a, b)$ argued that temperature is a major factor in maintaining the polymorphism in $T$. repens and that there was a linkage between the $A c$ gene (glucosidic forms) and genes concerned with fitness responses to temperature. If this is the case in $T$. repens there may well be no such genetic linkage in L. corniculatus. In both species the release of cyanide in leaves of cyanogenic phenotypes during tissue damage has no effect on photosynthesis or respiration because individuals or species may be partly or wholly resistant to HCN, thus conferring protection to the plant from grazing animals. However, the artificial addition of cyanide suggests that this is not the case.

Relatively severe drought reduced the rate of photosynthesis in all forms of $L$. corniculatus and $T$. repens. On the other hand, respiration was unaffected by the treatment in cyanogenic and acyanogenic phenotypes of the two species with the possible exception of the acyanogenic form of $L$. corniculatus. No satisfactory explanation can be given for this latter result. Thus the photosynthetic apparatus is more susceptible to drought but the moisture stress does not appear to be responsible for any release of cyanide from the cyanogenic tissues or if $\mathrm{CN}$ is released it has no inhibitory effect.

If winter temperature is the sole major selecting agent in $T$. repens it is difficult to understand why the populations remain polymorphic. Jones (1970) suggested that it is more likely that cyclic effects of temperature are of consequence in T. repens, influencing the glucosidic form. He also argued that the effect of January mean temperature may be on the distribution of the animals which eat $L$. corniculatus and $T$. repens rather than on the plants directly; these two explanations need not be mutually exclusive. 
The influence of cyclic drought may also be of significance in the maintenance of the polymorphism of cyanogenesis in wild populations of the two species.

Acknoweledgments.-We wish to express our grateful appreciation to Professor D. A. Jones and Dr I. Ridge for their advice and encouragement. We are also indebted to Dudley College of Education for the facilities and equipment which have allowed us to undertake the research.

\section{REFERENCES}

CORKILL, L. 1940. Cyanogenesis in white clover (Trifolium repens L.). I. Cyanogenesis in single plants. N.Z. F. Sci. Tech., 22, 65B-67B.

DADAY, H. 1954a. Gene frequencies in wild populations of Trifolium repens. L. I. Distribution by latitude. Heredity, $8,61-78$.

DADAY, н. 1954b. Gene frequencies in wild populations of Trifolium repens L. II. Distribution by altitude. Heredity, 8, 377-384.

DADAY, H. 1965. Gene frequencies in wild population of Trifolium repens L. IV. Mechanisms of natural selection. Heredity, 20, 355-365.

DIXON, M., AND WEBB, E. C. 1966. Enzymes. Longmans, London.

roulds, W., AND GRIME, J. P. 1972. The influence of soil moisture on the frequency of cyanogenic plants in populations of Trifolium repens and Lotus corniculatus. Heredity, $28,143-146$.

JONEs, D. A. 1970. On the polymorphism of cyanogenesis in Lotus corniculatus L. III. Some aspects of selection. Heredity, 25, 633-641.

JONES, D. A. 1972. On the polymorphism of cyanogenesis in Lotus corniculatus L. IV. The Netherlands. Cenetica, 43, 394-406.

i unJRGÅRdH, H. 1966. Plant Physiology. Oliver and Boyd.

MARSH, P. B. AND GODDARD, G. R. 1939. Respiration and fermentation in the carrot, Daucus carota. I. Respiration. Am. J. Bot., 20, 724-728.

MELVILLE, J., COOP, I. E., DOAK, B. W., AND REIFER, I. 1940. Cyanogenesis in white clover (Trifolium repens L.). IV. Methods of determination and general considerations. N.Z.J. Sci. Tech., 22, 144B-154B.

zhukovsкi, р. м. 1956. The forage value of Lotus corniculatus. Dokl, Vses. Akad. Sel'skokloz Nauk, 9, 24-28. 